\title{
Synthesis of Titanium Oxide Photocatalyst Supported on Spherical Porous Hydroxyapatite
}

\author{
Narumi Yoshijima $^{1}$, Kengo Tamazawa ${ }^{2}$, Ayu Kodaira ${ }^{3}$, and Toru Nonami ${ }^{1 *}$ \\ 1 Mechanical and Systems Engineering School of Technology, Chukyo University, \\ 101-2 Yagotohonmachi, Showa-ku, Nagoya, Aichi Prefecture, Japan 466-8666 \\ 2 Graduate School of Information Science, Chukyo University Graduate School, \\ 101-2 Yagotohonmachi, Showa-ku, Nagoya, Aichi Prefecture, Japan 466-8666 \\ 3 Institute for Advanced Studies in Artificial Intelligence, \\ Chukyo University Institute for Advanced Studies in Artificial Intelligence, 101-2 Yagotohonmachi, Showa-ku, \\ Nagoya, Aichi Prefecture, Japan 466-8666 \\ * Corresponding author: Fax: +81-52-835-7956, e-mail: tnonami@sist.chukyo-u.ac.jp
}

\begin{abstract}
We report the synthesis of a photocatalytic composite of spherical porous hydroxyapatite (sHAp) and $\mathrm{TiO}_{2}$. sHAp was prepared by a wet method using simulated body fluid as a slurry and was then mixed with a $\mathrm{TiO}_{2}$ sol to obtain the sHAp $+\mathrm{TiO}_{2}$ composite. The $\mathrm{TiO}_{2}$ content of sHAp + $\mathrm{TiO}_{2}$ was $\sim 7.8$ wt. \%. $\mathrm{sHAp}+\mathrm{TiO}_{2}$ showed photocatalytic activity that was more than ten times greater than that of $\mathrm{TiO}_{2}$ even under irradiation with the low-intensity ultraviolet (UV) light of a fluorescent lamp. $\mathrm{Mb}$ decomposition of $58.2 \%$ was achieved under UV light with an intensity of $7.60 \times 10^{2} \mu \mathrm{W} \mathrm{cm}{ }^{-2}$ using the $\mathrm{sHAp}+\mathrm{TiO}_{2}$ composite, which is significantly higher than the $8.05 \%$ achieved using only $\mathrm{TiO}_{2}$. Thus, the composite material showed higher activity than that of unsupported $\mathrm{TiO}_{2}$. Furthermore, $\mathrm{sHAp}+\mathrm{TiO}_{2}$ could oxidize leucocrystal violet (LCV) to crystal violet (CV) even after being placed in the dark for $120 \mathrm{~h}$. The positively charged holes are suggested to persist on $\mathrm{TiO}_{2}$ because of the electron withdrawing effects of sHAp and can contribute to LCV oxidation. Thus, the photocatalytic activity of $\mathrm{TiO}_{2}$ was improved by using sHAp as a support.
\end{abstract}

Key words: Photocatalyst, titanium, hydroxyapatite, photo-oxidation, composite.

\section{INTRODUCTION}

The pollution of the environment by harmful chemicals is a serious problem that necessitates the development of new purification technologies and materials. We previously reported the use of composites of $\mathrm{TiO}_{2}$ photocatalysts and hydroxyapatite (HAp) as environmental purification materials [1-4]. $\mathrm{TiO}_{2}$ is a chemically stable photocatalyst that can decompose harmful chemicals. It has been used to deodorize air by eliminating NOx, and as an antibacterial material [5-9]. The band gap energy of anatase $\mathrm{TiO}_{2}(3.2 \mathrm{eV})$ enables it to absorb ultraviolet (UV) light with wavelengths of $<380$ nm.

When electrons in the valence band of $\mathrm{TiO}_{2}$ are excited to the conductance band, positively charged holes are left behind in the conduction band [10]. The reaction of these holes with water on the crystal surface leads to the formation of hydroxyl radicals $(\cdot \mathrm{OH})$. These radicals are stronger oxidizing agents than ozone and can decompose harmful chemicals [11-13].

Therefore, it is important that the target substance can reach the surface of the catalyst to allow photocatalytic reactions, such as decomposition, to occur. This problem can be solved by using a photocatalyst that has been suitably modified such that the target substance adheres to the catalyst surface. It is desirable to include the ability to both bind and decompose the target substance using light, and this combination of functions can be achieved through the hybridization of adhesive substances, such as activated carbon or zeolites, with a photocatalyst, such as $\mathrm{TiO}_{2}[11$, 14].

If $\mathrm{TiO}_{2}$ is directly mixed into an organic resin, the resin itself may be oxidized and decomposed. This undesirable photodegradation of the catalyst matrix has hampered efforts to extend the range of applications of photocatalysts. Taoda et al. [15] developed "muskmelon $\mathrm{TiO}_{2}$ photocatalytic particles" to solve this problem, in which silica covers the $\mathrm{TiO}_{2}$ surface like the mask of a muskmelon, and Nonami et al. [1-4] developed HAp-covered $\mathrm{TiO}_{2}$, a composite ceramic in which plate-like crystals of $\mathrm{HAp}$ cover the $\mathrm{TiO}_{2}$ surface.

In these materials, the surface of $\mathrm{TiO}_{2}$ is covered with non-photoactive silica or HAp, so $\mathrm{TiO}_{2}$ does not directly encounter the resin, and resin decomposition is prevented. The part of author et al. reported that in HAp-covered $\mathrm{TiO}_{2}$, the electrons generated at the $\mathrm{TiO}_{2}$ surface migrate towards HAp, which holds them and helps to suppress electron-hole recombination and may result in improved photocatalytic activity [16].

This composite material was obtained by precipitating fine apatite crystals on the surface of titanium oxide thin films or particles. However, an excessive amount of precipitated apatite could completely cover the titanium oxide surface, causing a loss of photocatalytic activity. Thus, the apatite content of this composite material was as low as $1-5 \%$, which may be insufficient to accommodate the electrons generated in the photocatalytic reaction. Furthermore, the apatite content in the composite material 
is small, and the ability of apatite to adsorb the target substance is not sufficient.

HAp is a form of calcium phosphate and a major component of teeth and bones [17]. It has excellent biocompatibility and can absorb various substances by electrostatic attraction [18-20]. It is also an excellent material for ion exchange, and HAp derivatives with different physical properties can be manufactured by the substitution of various elements [21]. Nakane et al. used the fact that the hydroxide groups of HAp can be easily exchanged for fluoride to improve the acid tolerance of $\mathrm{HAp}$, and developed a fluorinated $\mathrm{HAp}$-covered $\mathrm{TiO}_{2}$ [22].

Kodeira et al. reported the synthesis of spherical porous hydroxyapatite (sHAp) by a wet method using simulated body fluid [23]. sHAp is a form of HAp containing aggregates of plate-shaped crystals that form particles with a diameter of $0.1-0.5 \mu \mathrm{m}$ and with gaps of a maximum size of $\sim 0.4 \mu \mathrm{m}$ between the aggregated plate-shaped $\mathrm{TiO}_{2}$ The synthesis of a sHAp $+\mathrm{TiO}_{2}$ composite material, in which fine $\mathrm{TiO}_{2}$ particles are supported within the gaps between the plate-shaped crystals of sHAp, was first reported by our group [24]. The HAp content of this composite material can be $90 \mathrm{wt} \%$ or more. As the HAp content increases, the possibility of HAp capturing the electrons generated in the photocatalytic reaction increases.

Therefore, more of the electrons generated by the photocatalytic reaction are prevented from recombining with holes, and the photocatalytic activity of the composite material is improved. In addition, the high apatite content of the composite material allows the adsorption abilities of HAp to be demonstrated.

The following three behaviors are expected to occur in sHAp $+\mathrm{TiO}_{2}$ composites:

(1) $\mathrm{TiO}_{2}$ is contained between the tabular crystals of apatite and is not exposed. Therefore, even when mixed with paint or other matrices, the photocatalyst does not come into direct contact with the resin binder and the matrix is not decomposed.

(2) Harmful chemicals adhere to sHAp and can then be decomposed by the $\mathrm{TiO}_{2}$ photocatalyst.

(3) As with HAp-covered $\mathrm{TiO}_{2}$, electron migration and capture can occur between sHAp and $\mathrm{TiO}_{2}$, leading to improved photocatalytic ability.

In this study, a sHAp $+\mathrm{TiO}_{2}$ composite was synthesized, and its photocatalytic properties were evaluated. The discoloration of aqueous solutions of methylene blue $(\mathrm{Mb})$ and changes in the color of leucocrystal violet (LCV) under different intensities of UV illumination were also demonstrated. The part of author et al. [16] have previously reported photocatalytic decomposition using HAp under high-intensity UV irradiation. However, we herein illustrate a significant reduction in the UV irradiation intensity required to achieve high levels of photodegradation using sHAp-supported composites, which do not obstruct the catalytic $\mathrm{TiO}_{2}$ surface. Our sHAp composite material showed photocatalytic activity even under irradiation with a typical fluorescent lamp, making it suitable for realistic environmental remediation applications.

2. Experimental

2.1 Synthesis of sHAp
The sHAp support was synthesized from simulated body fluid. An aqueous solution of $\mathrm{CaCl}_{2} \cdot 2 \mathrm{H}_{2} \mathrm{O}$ was mixed into phosphate-buffered saline $(\mathrm{PBS})\left([\mathrm{NaCl}]=54.8 \mathrm{mmol} \mathrm{L}^{-1}\right.$, $[\mathrm{KCl}]=1.074 \mathrm{mmol} \mathrm{L}^{-1},\left[\mathrm{KH}_{2} \mathrm{PO}_{4}\right]=0.588 \mathrm{mmol} \mathrm{L}^{-1}$, and $\left[\mathrm{Na}_{2} \mathrm{HPO}_{4}\right]=3.24 \mathrm{mmol} \mathrm{L}^{-1}$ ) to obtain a $\mathrm{Ca}: \mathrm{P}$ mole ratio of 0.300 , and the mixture was stirred for $1 \mathrm{~h}$ while the temperature was maintained at $40{ }^{\circ} \mathrm{C}$ using a water bath (SRS266PA, Advantec). The mixture was left undisturbed for 1 day, after which it was decanted. Desalination was carried out using a centrifugal separator (5420, Kubota) until the conductance using an electroconductivity meter (MPC227, Mettler) was less than $150 \mu \mathrm{S} \mathrm{cm}^{-1}$.

\subsection{Preparation of sHAp $+\mathrm{TiO}_{2}$ composite}

A slurry of sHAp $(0.2 \mathrm{~g})$ and a $\mathrm{TiO}_{2}$ sol (TKS-203, Tayca Corporation) were mixed in $1 \mathrm{~L}$ of water and stirred for $1 \mathrm{~h}$. The $\mathrm{TiO}_{2}$ sol was prepared such that its $\mathrm{TiO}_{2}$ content was $0.2 \mathrm{~g}$ per $0.2 \mathrm{~g}$ of sHAp. After letting the mixture stand for 1 day, it was decanted and washed with a centrifugal separator until the water contained no further suspended material. Subsequently, the composite was dried for use in further studies. $\mathrm{TiO}_{2}$ sol (TKS-203, Tayca Corporation) was used as the $\mathrm{TiO}_{2}$ sample.

2.3 Scanning electron microscopy

The shape and surface of sHAp were studied using scanning electron microscopy (SEM) (S-2600, Hitachi Seisakusho) at an acceleration voltage of $15.0 \mathrm{kV}$.

\subsection{Identification and analysis}

sHAp was identified and its crystal structure verified using powder X-ray diffraction (XRD) (Rigaku MiniFlex, Rigaku) with a scan speed of $2.00^{\circ}$ min- 1 and a $\mathrm{Cu} \mathrm{K \alpha}$ $\mathrm{X}$-ray source. Energy dispersive X-ray spectroscopy (EDXS) was used to identify the elemental composition of the surface of the composites (InTouchScopeTM scanning electron microscope JSM-IT100, JEOL - Japan Electro Optical Laboratory).

\subsection{Specific surface area}

The specific surface area was measured using the Brunauer-Emmett-Teller (BET) method, using nitrogen and helium gas to measure adsorption and desorption isotherms (Monosorb MS-21, Yuasa Ionics).

\subsection{Zeta potential}

The zeta potential of each sample was measured after 10 min with a surface potential measuring device (Zeta Nanosizer Nano Series Nano-Z; manufactured by Sysmex Corporation). The set temperature was $20^{\circ} \mathrm{C}$, and a He-Ne laser $(633 \mathrm{~nm})$ was used as a light source.

2.7 Field-emission scanning electron microscope

We observed high magnification of the surface of the sHAp $+\mathrm{TiO}_{2}$ composite with field-emission scanning electron microscopy (FE-SEM) (JSM-7800F, Japan Electro Optical Laboratory) at acceleration voltages of $0.500-2.00 \mathrm{kV}$.

\subsection{X-ray fluorescence spectrometry}

Quantitative analysis of the containing elements of sHAp-supported $\mathrm{TiO}_{2}$ was performed using wavelength dispersive X-ray spectrometry using an X-ray fluorescence (XRF) spectrometer (ZSX100e, Rigaku) equipped with a 
Rh tube $(3 \mathrm{~kW}) \mathrm{X}$-ray generator.

2.9 Discoloration of an aqueous $\mathrm{Mb}$ solution

$\mathrm{TiO}_{2}(4.0 \mathrm{mg})$ and $\mathrm{HAp}+\mathrm{TiO}_{2}(50 \mathrm{mg})$ powders were each added to an aqueous solution of $\mathrm{Mb}(50 \mathrm{~mL}, 10 \mathrm{ppm})$. These solutions were stirred in the dark for $30 \mathrm{~min}$ and then irradiated with a blacklight (Sankyo Denki, 27W) for $90 \mathrm{~min}$ at three levels of UV intensity $\left(3.60 \times 10^{3}, 7.50\right.$ $\times 10^{2}$, or $2.00 \times 10^{2} \mu \mathrm{W} \mathrm{cm}^{-2}$ ).

The absorbance of $\mathrm{Mb}$ at $660 \mathrm{~nm}$ was measured using a ratio beam spectrophotometer (U-5100, Hitachi) at $10 \mathrm{~min}$ intervals. A similar experiment was also performed using a fluorescent lamp (Panasonic, 32W, ultraviolet light intensity $2.00 \mu \mathrm{W} \mathrm{cm}{ }^{-2}$ ) as the irradiation source.

\subsection{Observation of LCV color changes}

$\mathrm{TiO}_{2}(10.0 \mathrm{mg})$ and sHAp $+\mathrm{TiO}_{2}(100 \mathrm{mg})$ powders were each irradiated by a blacklight (UV intensity of 5.40 $\left.\times 10^{3} \mu \mathrm{W} \mathrm{cm} \mathrm{cm}^{-2}\right)$ for $6 \mathrm{~h}$. LCV $(0.10 \mathrm{~g})$ was then mixed into each of the powders, and the color of the mixtures was observed after leaving them to stand in the dark for either 24 or $120 \mathrm{~h}$

\section{Results and Discussion}

3.1 Synthesis of sHAp

Fig. 1 shows SEM images of the synthesized sHAp spheres, which arise from the aggregation of plate-shaped particles of $\sim 0.1-0.5 \mu \mathrm{m}$ in size. The particle diameter was averaged over $\sim 50$ particles and found to be $\sim 1-5 \mu \mathrm{m}$, and gaps exist between the aggregated plate-shaped crystals.

The (002), (211), (112), and (300) reflections of HAp were observed in the powder XRD pattern of sHAp, as shown in Fig. 2. The ratios of the diffraction intensity peaks for each crystal surface in the diffraction pattern were checked. The peaks that appear near $2 \theta=25.7^{\circ}$ and $33.0^{\circ}$ correspond to the $c(002)$ and $a$ (300) surfaces, respectively. In contrast to the case for regular apatite, the intensity of the (002) reflection of sHAp is greater than that of the (004) reflection. This difference in intensity suggests that the plate-shaped HAp crystals grow in either the $a$ or $b$ directions, leaving many c faces exposed, which matches the results of SEM imaging.
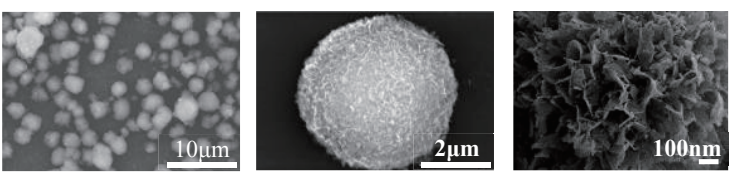

Fig. 1 SEM images of sHAp particles at various magnification levels.

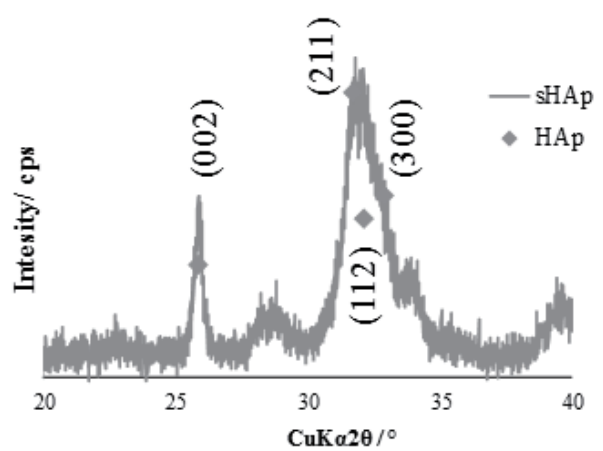

Fig. 2 XRD diffraction pattern of sHAp and peak intensities of HAp

\subsection{Synthesis of $\mathrm{sHAp}+\mathrm{TiO}_{2}$ composites}

Fig. 3 shows FE-SEM images of the $\mathrm{sHAp}+\mathrm{TiO}_{2}$ composite. Fine particles of $\sim 30-50 \mathrm{~nm}$ in size are supported on the sHAp surface, which was confirmed to consist of $\mathrm{TiO}_{2}$ by the detection of $\mathrm{Ti}$ in these particles by EDXS analysis. As shown in Fig. 3(b), the $\mathrm{TiO}_{2}$ particles were mainly supported on the surfaces of the plate-shaped sHAp crystals, and the pores were not completely closed. Therefore, the sHAp surface was not completely covered by $\mathrm{TiO}_{2}$ and remained available for adsorption.

Table I shows specific surface area and zeta potential values. The surface area of sHAp $+\mathrm{TiO}_{2}$ was larger than the respective values of sHAp and $\mathrm{TiO}_{2}$. This is because $\mathrm{TiO}_{2}$ did not aggregate and was well dispersed and supported in the sHAp pores as shown in Fig 3.

Furthermore, XRF analyses (Table II) showed that the $\mathrm{TiO}_{2}$ concentration in the sHAp $+\mathrm{TiO}_{2}$ composite was $\sim 7.7$ wt \%. The calcium-to-phosphorus molar ratio of sHAp was calculated to be 1.78 . This is slightly larger than apatite's stoichiometric composition of 1.67.

\section{(a)}

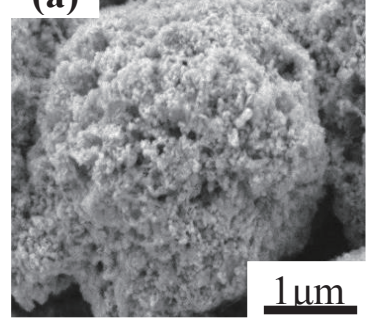

(b)

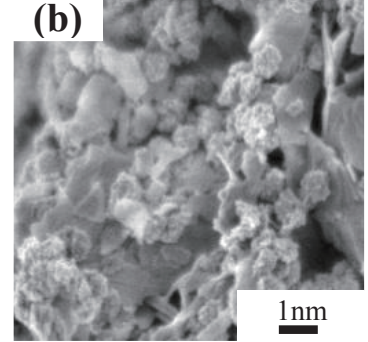

Fig. 3 FE-SEM Images of sHAp + $\mathrm{TiO}_{2}$ : (a) general view, (b) enlarged view

Table I. The specific surface area and zeta potential

\begin{tabular}{lll}
\hline Sample & $\begin{array}{l}\text { Specific surface } \\
\text { area } / \mathrm{m}^{2} / \mathrm{g}\end{array}$ & Zeta potential $/ \mathrm{mV}$ \\
\hline $\mathrm{sHAp}$ & 89.3 & -6.66 \\
$\mathrm{TiO}_{2}$ & 97.6 & -60.3 \\
$\mathrm{sHAp}+\mathrm{TiO}_{2}$ & 105 & -21.3 \\
$\mathrm{Mb}$ & - & 8.82 \\
\hline
\end{tabular}

Table II. Composition weight of $\mathrm{sHAp}+\mathrm{TiO}_{2}$ analyzed by SQX

\begin{tabular}{lc}
\hline Composition & Content $/$ wt $\%$ \\
\hline $\mathrm{CaO}$ & 59.09 \\
$\mathrm{P}_{2} \mathrm{O}_{3}$ & 32.54 \\
$\mathrm{TiO}_{2}$ & 7.77 \\
$\mathrm{Na}_{2} \mathrm{O}$ & 0.45 \\
\hline
\end{tabular}

3.3 Discoloration of methylene blue solutions

The decolorization test results of the $\mathrm{Mb}$ aqueous solution are shown in Fig. 4 (a) to (e). When $\mathrm{TiO}_{2}$ was added to the $\mathrm{Mb}$ aqueous solution and stirred in the dark for 30 minutes, the $\mathrm{Mb}$ aqueous solution decolorized about $60 \%$. On the other hand, sHAp $+\mathrm{TiO}_{2}$ and sHAp hardly decolorized the $\mathrm{Mb}$ aqueous solution in the dark. As shown in Table 1, since $\mathrm{TiO}_{2}$ is negatively charged, it was expected to be able to adsorb the positively charged $\mathrm{Mb}$. As shown in Table 1, all the materials are negatively 
charged. Among these materials, $\mathrm{TiO}_{2}$ has the largest difference in zeta potential with methylene blue. Therefore, it can be said that $\mathrm{TiO}_{2}$ adsorbs most $\mathrm{Mb}$ in the dark. A $13.2 \%$ reduction in the concentration of an aqueous $\mathrm{Mb}$ solution (Fig. 4) after 90 min of irradiation with $3.60 \times 10^{3}$ $\mu \mathrm{W} \mathrm{cm}$ co $^{-2}$ UV light (approximately the same intensity as that of a clear outdoor sky) was observed for unsupported $\mathrm{TiO}_{2}$, while the equivalent irradiation led to a $71.6 \%$ reduction in the $\mathrm{Mb}$ concentration when $\mathrm{sHAp}+\mathrm{TiO}_{2}$ was used. UV irradiation with an intensity of $7.60 \times 10^{2} \mu \mathrm{W}$ $\mathrm{cm}^{-2}$ (approximately equivalent to that of sunlight through a window) resulted in $\mathrm{Mb}$ concentration reductions of 8.05 and $58.2 \%$ for unsupported $\mathrm{TiO}_{2}$ and $\mathrm{sHAp}+\mathrm{TiO}_{2}$, respectively. A UV intensity of $2.00 \times 10^{2} \mu \mathrm{W} \mathrm{\textrm {cm } ^ { - 2 }}$ (approximately equivalent to the intensity of a cloudy outdoor sky) led to reductions of $3.07 \%$ and $31.2 \%$ for unsupported $\mathrm{TiO}_{2}$ and $\mathrm{sHAp}+\mathrm{TiO}_{2}$, respectively. Thus, the photocatalytic activity of the $\mathrm{sHAp}+\mathrm{TiO}_{2}$ composite was higher than that of unsupported $\mathrm{TiO}_{2}$ at each of these UV intensities.
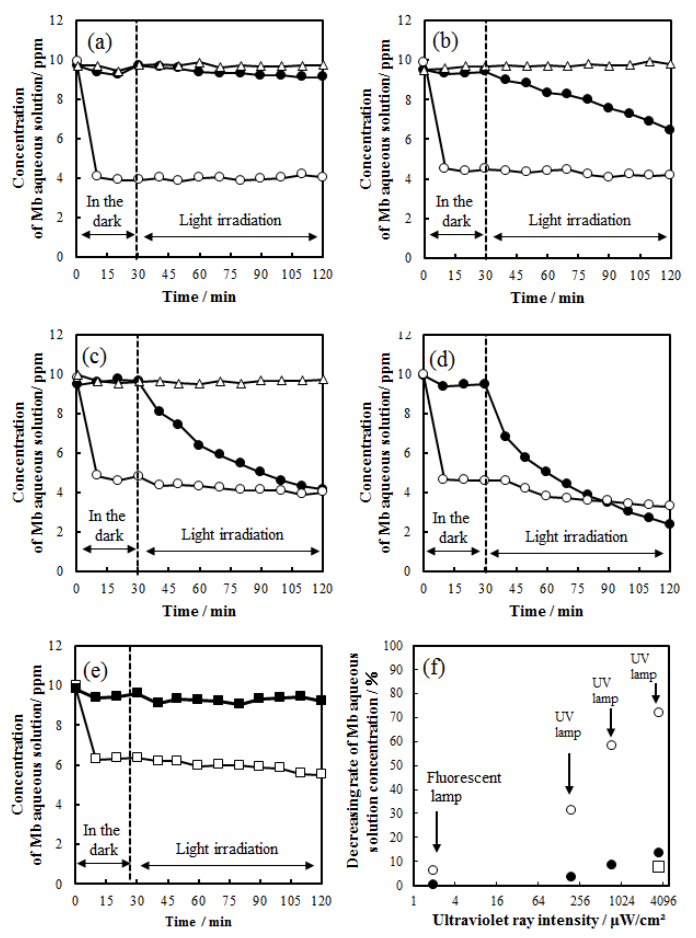

Fig. 4 Changes in the concentration of the Mb aqueous solution when each sample was added and processed (placed in a dark place for 30 minutes and then irradiated with light). Sample legend: $\mathrm{sHAp}+\mathrm{TiO}_{2}(\mathbf{O}), \mathrm{TiO}_{2}(\bigcirc)$, sHAp (ם), without sample $(\triangle)$, sHAp and $\mathrm{TiO}_{2}$ (Each compound was added without complex treatment) ( $\square$ ),(a)-(e) Relationship between test time and $\mathrm{Mb}$ concentration when the sample is added.(a)Irradiate with fluorescent lamp (UV intensity; $2.00 \mu \mathrm{W} \quad \mathrm{cm}^{-2}$ ),(b) Irradiate with UV (UV intensity; $2.00 \times 10^{2} \mu \mathrm{W} \mathrm{cm} \mathrm{cm}^{-2}$ ), (c) Irradiate with UV (UV intensity; $7.50 \times 10^{2} \mu \mathrm{W} \mathrm{cm}{ }^{-2}$ ), (d), (e) Irradiate with UV (UV intensity; $3.60 \times 10^{3} \mu \mathrm{W}$ $\mathrm{cm}^{-2}$ ),(f) Percentage reduction in the concentration of an aqueous $\mathrm{Mb}$ solution when irradiated with either UV or fluorescent light in the presence of $\mathrm{sHAp}+\mathrm{TiO}_{2}$ or $\mathrm{TiO}_{2}$.

When a typical fluorescent lamp was used to irradiate aqueous $\mathrm{Mb}$ solutions for $90 \mathrm{~min}$, no reduction in the $\mathrm{Mb}$ concentration was observed in the presence of unsupported $\mathrm{TiO}_{2}$, while a reduction of $6.19 \%$ was observed for the sHAp $+\mathrm{TiO}_{2}$ composite. This result implies that even irradiation with a weak UV source such as a fluorescent lamp activates the catalytic activity of the sHAp $+\mathrm{TiO}_{2}$ composite.

On the other hand, as shown in Fig. 4 (e), when simply adding sHAp $(50 \mathrm{mg})$ and $\mathrm{TiO}_{2}(4.0 \mathrm{mg})$ to $50 \mathrm{~mL}$ of the $\mathrm{Mb}$ aqueous solution to obtain the same $\mathrm{sHAp} / \mathrm{TiO}_{2}$ ratio as in the sHAp $+\mathrm{TiO}_{2}$ composite material, the $\mathrm{Mb}$ aqueous solution was hardly decolorized. When simply added sHAp and $\mathrm{TiO}_{2}$ to the $\mathrm{Mb}$, the $\mathrm{Mb}$ concentration decreased in the dark. On the other hand, when sHAp was mixed alone, the $\mathrm{Mb}$ concentration did not decrease in the dark. Therefore, it is considered that $\mathrm{Mb}$ was adsorbed to $\mathrm{TiO}_{2}$ in the dark. Therefore, no photocatalytic activity improvement occurs if the sHAp and $\mathrm{TiO}_{2}$ are present separately, and the composite structure with titanium oxide supported in the pores of apatite is necessary to improve the photocatalytic activity.

The part of author et al. [16] reported that although the rate of the photocatalytic oxidation reaction depends on the surface area of the photocatalyst, the reaction rate was higher in the case of HAp-covered $\mathrm{TiO}_{2}$, which has a smaller specific surface area than commercial $\mathrm{TiO}_{2}$. Therefore, it was proposed that the HAp crystal holds the electrons separate from the holes and suppresses the recombination of the electrons with positive holes, thereby increasing the $\mathrm{Mb}$ decomposition rate. The specific surface area of $\mathrm{sHAp}+\mathrm{TiO}_{2}$ synthesized in this study is very large (Table 1). Similarly, in the case of the sHAp + $\mathrm{TiO}_{2}$ composite material synthesized in this work, it may be concluded that the photocatalytic activity increased due to the electron holding ability of sHAp, which resulted in an improvement of the efficiency of $\mathrm{Mb}$ decomposition (Fig. 4).

The part of author et al. [16] reported the $\mathrm{Mb}$ decomposition rate when irradiated with UV light was about 2.5 times higher than that of titanium oxide, but no experiments of the decomposition of Mb under weak UV sources were conducted.

The sHAp $+\mathrm{TiO}_{2}$ composite prepared herein had a sHAp content of $>90 \mathrm{wt} . \%$, which we suggest led to the more than five-fold enhancement in the $\mathrm{Mb}$ decomposition rate of $\mathrm{sHAp}+\mathrm{TiO}_{2}$ compared to unsupported $\mathrm{TiO}_{2}$. In this composite material, the fine $\mathrm{TiO}_{2}$ particles in the pores of sHAp are surrounded by sHAp to a greater degree than in the previously reported $\mathrm{HAp}$-coated $\mathrm{TiO}_{2}$ [16]. When irradiated with a weak UV source, the $\mathrm{Mb}$ resolution capability of $\mathrm{sHAp}+\mathrm{TiO}_{2}$ increased to more than ten times that of $\mathrm{TiO}_{2}$ (Fig. 4). In addition, the increased sHAp content of the sHAp $+\mathrm{TiO}_{2}$ composite provides improved adsorption. The decomposition rate became very poor when sHAp and $\mathrm{TiO}_{2}$ were used separately (Fig.4), so the composite structure is important for improving the photocatalytic ability.

\subsection{Changes in leucocrystal violet color}

Fig. 5 shows the changes in the color of mixtures of both sHAp $+\mathrm{TiO}_{2}$ with LCV and unsupported $\mathrm{TiO}_{2}$ with $\mathrm{LCV}$ after irradiation. Whereas the mixture of unsupported $\mathrm{TiO}_{2}$ and LCV remained almost white after $120 \mathrm{~h}$, the mixture of sHAp $+\mathrm{TiO}_{2}$ and $\mathrm{LCV}$ changed from white to 
purple after only $24 \mathrm{~h}$ and continued to deepen in color up to $120 \mathrm{~h}$. Since the oxidation of $\mathrm{LCV}$ to $\mathrm{CV}$ is accompanied by a color change from white to purple [7], we conclude that sHAp $+\mathrm{TiO}_{2}$ enhances the rate of oxidation of $\mathrm{LCV}$, causing it to change color more rapidly. The irradiation of sHAp $+\mathrm{TiO}_{2}$ with ultraviolet light causes the photogenerated electrons from $\mathrm{TiO}_{2}$ to be captured by sHAp, which suppresses electron-hole recombination. The positive holes that remain in $\mathrm{TiO}_{2}$ contribute to the oxidation of LCV.

\begin{tabular}{|c|c|c|c|}
\hline \multirow{2}{*}{ Sample } & \multicolumn{3}{|c|}{ Dark Time } \\
\hline & $\mathrm{Oh}$ & $24 \mathrm{~h}$ & $120 \mathrm{~h}$ \\
\hline \multicolumn{4}{|l|}{$\mathrm{TiO}_{2}$} \\
\hline sHAp $+\mathrm{Ti}$ & & & \\
\hline
\end{tabular}

Fig. 5 Change in the color of LCV with time. Samples were each irradiated by a blacklight for $6 \mathrm{~h}$. LCV was then mixed into each of the powders the mixture was left to stand in the dark for either 24 or $120 \mathrm{~h}$.

\section{Conclusions}

In this work, a sHAp $+\mathrm{TiO}_{2}$ composite was synthesized by mixing sHAp, obtained by a wet method using simulated body fluid, and a $\mathrm{TiO}_{2}$ sol. The photocatalytic properties of this composite material were evaluated. Irradiating the composite photocatalyst with UV from a blacklight at three intensity levels showed that the percentage reduction in the concentration of an aqueous $\mathrm{Mb}$ solution was greater for $\mathrm{sHAp}+\mathrm{TiO}_{2}$ than for unsupported $\mathrm{TiO}_{2}$, regardless of the UV intensity. We achieved an $\mathrm{Mb}$ degradation rate more than 5 times higher than that of unsupported $\mathrm{TiO}_{2}$.

$\mathrm{TiO}_{2}$ did not decompose $\mathrm{Mb}$ even when irradiated with a fluorescent lamp, but sHAp $+\mathrm{TiO}_{2}$ decomposed a solution of $\mathrm{Mb}$ by $6.19 \%$. Since $\mathrm{sHAp}+\mathrm{TiO}_{2}$ showed a higher photocatalytic activity than unsupported $\mathrm{TiO}_{2}$ even under the low ultraviolet light intensity of a fluorescent lamp, we conclude that the sHAp support increased the photocatalytic activity of $\mathrm{TiO}_{2}$.

Furthermore, upon mixing LCV with $\mathrm{sHAp}+\mathrm{TiO}_{2}$ that had been irradiated with light and leaving the mixture in the dark, the mixture of sHAp $+\mathrm{TiO}_{2}$ oxidized the LCV to form purple-colored $\mathrm{CV}$ over time. Based on these results, we suggest that the electrons generated in the photocatalytic reaction move from $\mathrm{TiO}_{2}$ to sHAp.

This phenomenon helps to suppress the recombination of electrons with holes, and thus the photocatalytic activity is improved. It was predicted that the photocatalytic activity was improved because the electrons generated by the photocatalytic reaction moved from $\mathrm{TiO}_{2}$ to sHAp and HAp suppressed the recombination of electrons and holes by retaining the electrons. We propose that when the specimen is kept in the dark, the holes of $\mathrm{TiO}_{2}$ can still contribute to LCV oxidation because of the decreased electron-hole recombination provided by sHAp. This study synthesized a new composite material and showed that it could be used as a photocatalyst under fluorescent light and darkness. We believe that this new material will contribute to the future applications of $\mathrm{TiO}_{2}$ photocatalysts.

\section{References}

[1]T. Nonami, H. Taoda, N. T. Hue, E. Watanabe, K. Iseda, M. Tazawa, M. Fukaya, Mater. Res. Bull. 33, 125-131 (1998)

[2]T. Nonami, H. Hase, K. Funakoshi, Catalysis Today, 96, 113-118 (2004)

[3]T. Nonami, K. Kato, H. Taoda, Mater. Res. Soc. Symp. Proc. 549, 147-152 (1998)

[4]T. Nonami, H. Hase, K. Funakoshi, Materials Science Forum, 439, 337 -343 (2003)

[5]A. Fujishima, K. Honda, Bull. Chem. Soc. Jpn. 44, 1148-1150 (1971)

[6]A. Fujishima, K. Honda, Nature 238, 37-38 (1972)

[7]T. Hisanaga, K. Tanaka, J. Photochem. Photobiol. A Chem. 54, 113-118 (1990).

[8]K. Kato, A. Tsuzuki, H. Taoda, Y. Torii, T. Kato, Y. Butsugan, J. Mater. Sci. 29, 5911-5915 (1994)

[9]E. Pelizzetti, C. Minero, Electrochem. Acta 38, 47-55 (1993)

[10]A. L. Linsebigler, G. Lu, J. T. Yates, Jr., Chem. Rev. 95, 735-758 (1995)

[11]N. Areerachakul, S. Vigneswaran, H. H. Ngo, J. Kadasarmy, Separation and Purification Technology, 55, 206-211 (2007)

[12]R. Wang, K. Hashimoto, A. Fujishima, M. Chikuni, E. Kojima, A. Kitamura, M. Shimohigoshi, T. Watanabe, Nature, 388, 431-432 (1997)

[13]K. Tanaka, M. F. V. Capule, T. Hisanaga, Chemical Physics Letters 187, 73-76 (1991)

[14]Y. Liang, H. Wang, H. Sanchez Casalongue, Z. Chen, H. Dai, Nano Research, 3, 701-705 (2010)

[15]H. Taoda, Synthesiology-English edition, 1,263-272 (2009)

[16]K. Funakoshi, T. Nonami, J. Am. Ceram. Soc. 89, 944 $-948(2006)$

[17]K. Kato, H. Aoki, T. Tabata, M. Ogiso, Biomaterials, Medical Devices and Artificial Organs, 7, 291-297 (2009)

[18]T. Suzuki, T. Hatsushika, Y. Hayakawa, J. Chem. Soc. Faraday Trans. 177, 1059-1062 (1981)

[19]G. Bernardi, Methods Enzymol. 22, 325-339 (1971)

[20]G. Bernardi, M.G. Giro, C. Gaillard, Biochem. Biophys. Acta 278, 409-420 (1972)

[21]S. Kano, A. Yamazaki, R. Otsuka, M. Ohyagi, M. Akao, H. Aoki, Bio-Medical Materials and Engineering, 4, 283-290(1994)

[22]H. Nakane, S. Aoki, T. Nonami, K. Tanaka, M. Mori, K. Tone, T. Kameyama, J. Ceram. Soc. Jpn. 114, 838 843 (2006) [in Japanese]

[23]A. Kodaira, T. Nonami, H. Hase, J. Aust. Ceram. Soc. 47, 1 -5 (2011)

[24]K. Tamazawa, N. Yoshijima, A. Kodaira, T. Nonami, Report of the Microelectronics Symposium, 26th Autumn Meeting, 323-326 (2016). [in Japanese]

(Received August 7, 2017; Accepted September 20, 2017; Published Online December 1, 2017) 